\title{
PODER PÚBLICO E A PROTEÇÃO AO MEIO AMBIENTE
}

Nilton Carlos de Almeida Coutinho ${ }^{1}$

${ }^{1}$ Professor junto à Universidade do Oeste Paulista. Procurador do Estado de São Paulo, em exercício na Procuradoria Regional de Presidente Prudente. Especialista em Direito Penal, Direito Público e Planejamento e Gestão Municipal. Mestre em Direito pelo Centro de Ensino Universitário de Maringá. Doutorando em Direito pela Universidade Presbiteriana Mackenzie. Presidente da comissão do Advogado Público da 29a Subsecção da OAB/SP.

\section{RESUMO}

O presente trabalho procura analisar o papel do Estado enquanto ente obrigado constitucionalmente a proteger o meio ambiente, tendo como objetivo apresentar um estudo com base nos princípios que fundamentam a atuação estatal. Neste aspecto, o referido trabalho foi elaborado por meio de uma pesquisa exploratória por meio de análise bibliográfica e jurisprudencial, procurando apresentar ao leitor os princípios a serem utilizados como balizas pela Administração Pública em sua atuação, com vistas à proteção do meio ambiente o qual passa a ser analisado enquanto direito fundamental do ser humano.

Palavras-chave: Administração Pública; Meio Ambiente; Princípios Constitucionais.

\section{PUBLIC ADMINISTRATION AND ENVIRONMENTAL PROTECTION}

\begin{abstract}
The present work seeks analyze the State role as being constitutionally obliged to the environmental protection, with the aim of introducing a study based on the principles underlying the state action. In this aspect, this study was elaborated by a literature and jurisprudential exploratory research, showing to the reader the principles to be used as landmarks by the Public Administration in its operations, with a view to environmental protection, that begins to be analyzed as a human fundamental right.
\end{abstract}

Keywords: Public Administration; environment; constitutional principles. 


\section{INTRODUÇÃO}

Segundo dispõe 0 art. 225 da Constituição Federal de 1988, "Todos têm direito ao meio ambiente ecologicamente equilibrado, bem de uso comum do povo e essencial à sadia qualidade de vida, impondo-se ao Poder Público e à coletividade o dever de defendê-lo e preserválo para as presentes e futuras gerações".

Deste modo, observamos que foi atribuído ao Estado um importante papel na proteção ambiental. Tal papel decorre, entre outros fatores, do fato de o meio ambiente ser considerado um direito fundamental, tutelado pelo Estado e essencial para a manutenção do direito à vida e, em última análise, da dignidade da pessoa humana.

O presente trabalho baseia-se nas regras e princípios vigentes no Estado Brasileiro, com o objetivo de analisar a relação existente entre o poder estatal e a proteção ao meio ambiente.

Para assegurar a efetividade do direito ao meio ambiente a Constituição incumbiu o Poder Público de uma série de obrigações, as quais passamos a analisar.

\section{O PAPEL DO ESTADO NA PROTEÇÃO AMBIENTAL}

A primeira missão atribuída ao Estado consiste em preservar e restaurar os processos ecológicos essenciais e prover o manejo ecológico das espécies e ecossistemas e deriva do princípio da proteção à vida, uma vez que esta depende diretamente da proteção e preservação do meio ambiente.

Modernamente tem-se conceituado ecologia como a área da ciência que se dedica ao estudo das relações entre o mundo natural e os seres vivos, ou seja, é a ciência que estuda o meio ambiente, consoante assevera Carvalho (2004, p. 753.). Deste modo, na hipótese de degradação de um determinado ecossistema, deve-se procurar recuperá-lo, garantindo-se a salubridade e higidez do meio ambiente, ou seja: deve-se procurar manter as espécies vegetais e animais existentes, garantindo-se a continuidade e manutenção da Biodiversidade. Para auxiliar na proteção e manutenção dessas espécies foi criada a lei 9.985/00 a qual instituiu o Sistema Nacional de Unidades de Conservação da Natureza (SNUC)

Do mesmo modo, compete ao poder público preservar a diversidade e a integridade do patrimônio genético do País e fiscalizar as entidades dedicadas à pesquisa e manipulação de material genético.

Segundo Silva (2004, p. 44), o atendimento a este comando constitucional foi feito por meio da Medida Provisória n 2186-16, de 23 de agosto de 2001, a qual regulamentou o supracitado inciso. Esta medida, dentre outros assuntos, trata do acesso ao patrimônio genético e à tecnologia para conservação e utilização do meio ambiente, com o objetivo de protegê-lo, bem como à saúde humana. A medida provisória veda a utilização do patrimônio genético para práticas nocivas, tais como o desenvolvimento de armas biológicas e químicas.

A Constituição também incumbiu ao poder público a tarefa de definir, em todas as unidades da Federação, espaços territoriais e seus componentes a serem especialmente protegidos, sendo a alteração e a supressão permitidas somente por meio de lei, vedada qualquer utilização que comprometa a integridade dos atributos que justifiquem sua proteção;

Neste item, observa-se haver uma divergência na doutrina. Para alguns, o conceito de espaços territoriais especialmente protegidos aplica-se somente às unidades de conservação reguladas pela lei 9.985/00; ao passo que, para outros, tal conceito também abrangeria as áreas de preservação permanente.

Milaré (2004, p. 130) defende que a Constituição utilizou o termo em sentido estrito, 
abrangendo apenas as Unidades de Conservação típicas, ou seja: aquelas previstas na lei 9.985/00.

Nesse diapasão, tem-se que 0 art. $4^{0} \mathrm{da}$ lei $n^{\circ}$ 4.771, de 15 de setembro de 1965, (a qual institui o Código Florestal) foi recepcionado pela atual Constituição Federal. Entretanto, com base na nova ordem jurídica instalada, houve a necessidade de alteração da redação de tal artigo, de tal forma que, após a entrada em vigor da Medida Provisória no 2.166-67, de 2001, a supressão de vegetação em área de preservação permanente "somente poderá ser autorizada em caso de utilidade pública ou de interesse social, devidamente caracterizados e motivados em procedimento administrativo próprio, quando inexistir alternativa técnica e locacional ao empreendimento proposto".

Note-se que é permitido que a lei estabeleça hipóteses em que tal supressão ou alteração de espaços seja possível, respeitando, contudo, os princípios estabelecidos na Constituição Federal.

Outra importante missão conferida ao poder público consiste em exigir, na forma da lei, para instalação de obra ou atividade potencialmente causadora de significativa degradação do meio ambiente, estudo prévio de impacto ambiental, a que se dará publicidade.

O estudo de impacto ambiental constituise como um dos instrumentos da Política Nacional do Meio Ambiente e, dada sua relevância, será analisado em tópico específico.

A Constituição Federal incumbiu, ainda, ao poder público a função de controlar a produção, a comercialização e o emprego de técnicas, métodos e substâncias que comportem risco para a vida, a qualidade de vida e o meio ambiente.

Ora, em razão de a proteção ao meio ambiente constituir-se como um dos deveres do Estado, permitiu a Constituição Federal que o Poder Público interfira nas atividades econômicas de domínio privado com o objetivo de impedir danos à vida, à qualidade de vida ou ao meio ambiente. Tem-se, aqui, a aplicação do princípio do controle do poluidor pelo Poder público.

Com a percuciência de sempre, Prado (2005, p. 76) ensina que o direito ao ambiente ecologicamente equilibrado foi erigido à categoria de direito fundamental, em função da busca da melhoria da qualidade de vida e de bem-estar social indispensável à vida e ao desenvolvimento do ser humano. Valoriza-se, assim, a dignidade da pessoa humana e a sua qualidade de vida como dado vital inerente ao seu desenvolvimento enquanto pessoa.

Outro dever imposto ao poder público refere-se à promoção da Educação Ambiental em todos os níveis de ensino e a conscientização pública para a preservação do meio ambiente. No que se refere à Educação Ambiental observe-se que, segundo disposto na lei 9.795/99, entendese por educação ambiental os processos por meio dos quais o indivíduo e a coletividade constroem valores sociais, conhecimentos, habilidades, atitudes e competências voltadas para a conservação do meio ambiente, bem de uso comum do povo, essencial à qualidade de vida e sua sustentabilidade.

Assim, a fim de propiciar a adequada proteção ao meio ambiente, a Constituição Federal também estabeleceu que a Educação Ambiental deverá fazer parte dos currículos escolares, conscientizando-se a sociedade sobre a necessidade de preservação do meio ambiente.

A definição legal deixa claro que, por meio da Educação Ambiental, pretende-se formar uma consciência ambiental, de modo a propiciar o melhor gerenciamento e utilização dos recursos ambientais em benefício da humanidade.

Segundo Lanfredi (2007, p. 142) o modelo de Educação Ambiental criado "propõe posturas de integração e participação, de tal 
maneira que cada pessoa é incentivada a exercitar sua cidadania em plenitude".

Observe-se, por oportuno, que a própria Lei de Diretrizes e Bases da Educação (lei 9.394/96) inseriu a Educação Ambiental em sua proposta de Parâmetros Curriculares Nacionais, passando a fazer parte do currículo do Ensino Fundamental.

Tais medidas visam conscientizar os cidadãos sobre a importância da proteção do meio ambiente, face às conseqüências danosas que a sua violação pode trazer a todos os seres vivos.

Sobre o tema, Freitas (2001, p. 66) afirma que a Educação Ambiental é o mais eficaz meio preventivo de proteção ao meio ambiente.

Por fim, a Constituição Federal estabelece que é dever do Estado proteger a fauna e a flora, vedadas, na forma da lei, as práticas que coloquem em risco sua função ecológica, provoquem a extinção de espécies ou submetam os animais a crueldade.

Tal medida, assim como as anteriormente descritas, tem como objetivo proteger o direito à vida, por meio do correto gerenciamento dos recursos ambientais. A proteção à fauna, à flora e aos diversos ecossistemas existentes deve ser um objetivo presente na atividade estatal.

\section{FUNDAMENTOS PARA A ATUAÇÃO} ESTATAL

O artigo 37 da Constituição Federal proclama que a Administração Pública direta e indireta de qualquer dos Poderes da União, dos Estados, do Distrito Federal e dos Municípios obedecerá aos princípios de legalidade, impessoalidade, moralidade, publicidade e eficiência.

Tais princípios se constituem como a pedra angular na fixação de diretrizes para atuação estatal. Além deles, entretanto, torna-se possível relacionar os seguintes fundamentos, os quais se encontram diretamente relacionados com a proteção ao meio ambiente.

\subsection{Supremacia do interesse público}

Os poderes da conferidos à Administração Pública têm como objetivo permitir que esta desempenhe a contento o papel para o qual fora criada, qual seja: a satisfação do interesse público. Este, por sua vez, divide-se, segundo a doutrina, em interesse público primário e interesse público secundário. O primeiro pode ser identificado com o interesse da sociedade. Já o segundo é aquele no qual se objetiva 0 interesse da Administração Pública, enquanto ente estatal, ou seja, visa-se à consecução dos objetivos do governo.

Neste contexto, está se falando do que se convencionou chamar de interesse público primário, isto é, aquele diretamente ligado à coletividade, significando valorização da justiça, da segurança e do bem-estar. São esses, em suma, os interesses que devem preponderar.

Segundo Di Pietro (2005, p. 71) tem-se que a Administração Pública não pode atuar com vistas a prejudicar ou beneficiar pessoas determinadas, uma vez que é sempre o interesse público que tem que nortear 0 seu comportamento.

Pelo exposto há que se concluir que o interesse público que deve servir de baliza na ponderação de direitos fundamentais em colisão é aquele correspondente aos valores preconizados pela sociedade, bem como aos objetivos do Estado, eis que este representa os interesses dessa coletividade, sendo este 0 interesse público que deve ser levado em conta pelo Estado na tomada de decisão.

\subsection{Indisponibilidade do interesse púbico}

$\mathrm{Na}$ esfera administrativa, a denominada "indisponibilidade do interesse público" se justifica em função da natureza dos bens tutelados pela 
Administração Pública. Ora, o interesse público é, na verdade, o interesse do corpo social, da coletividade; razão pela qual o administrador não pode dele dispor, uma vez que este não lhe pertence. Nesse contexto, a Administração é um mero "curador" de interesses coletivos.

Por se tratarem de bens pertencentes a toda a sociedade, não encontram-se à livre disposição de quem quer que seja, pois se trata de bem de uso comum do povo, possuindo caráter indisponível. Tal princípio também se aplica às questões ambientais, eis que, por ser o meio ambiente um direito de todos (art. 225, CF), e ser um bem de uso comum do povo, tem-se que possui ele caráter indisponível. Para Di Pietro (2005) tal indisponibilidade visa conferir aos bens jurídicos tutelados, maior proteção pelo ordenamento jurídico, permitindo-se a adoção de medidas protetivas sempre que forem eles ameaçados ou violados.

Neste sentido, Bandeira de Mello (1995, p. 28) assevera que todo o sistema de direito administrativo, se constrói sobre os mencionados princípios da supremacia do interesse público sobre o particular e indisponibilidade do interesse público pela administração.

\subsection{Princípio da natureza pública da proteção ambiental}

Tal princípio foi expressamente previsto na Constituição Federal de 1988, fundamenta-se no fato de que, em razão da meio ambiente constituir-se como um bem de uso comum do povo, a proteção ambiental deve ser feita visando o bem-estar da coletividade, O princípio da natureza pública da proteção ambiental, ainda serve como fundamento para a obrigatoriedade da intervenção do Estado, eis que se trata de direito relacionado ao interesse público.

Para vários autores, poder-se-ia falar na existência de um princípio da obrigatoriedade da intervenção estatal $^{1}$. Por essa razão, quando se fala em proteção ambiental, há que se ter em mente que a indisponibilidade de tal interesse, bem como a supremacia do interesse público se constituem como fatores orientadores de sua proteção.

Logo, por se tratar de um bem de uso comum do povo (art. 225 da CF), o meio ambiente ecologicamente equilibrado não se insere entre os bens suscetíveis de disponibilidade pelo Estado, de tal forma que a proteção ambiental deve procurar assegurar a qualidade de vida e saúde de toda a sociedade, sobrepondo-se a interesses individuais.

\subsection{Princípio do controle do poluidor pelo Poder Público}

Conforme já se teve a oportunidade de dizer, ao Estado foi atribuído o dever de proteger o meio ambiente. E, para tanto, ele deve fiscalizar e orientar os cidadãos quanto aos limites para a adequada utilização do meio ambiente, o que é feito por meio das polícias administrativas. Nesta ótica, o princípio do controle do poluidor pelo Poder Público possibilita a realização de intervenções estatais visando à manutenção, preservação e restauração dos recursos ambientais, de modo a possibilitar sua utilização nacional e disponibilidade permanente. Encontrase previsto em nosso ordenamento jurídico, o art. 225, § $1^{\circ}, \mathrm{V}$, da Constituição Federal, o qual estabelece que é da incumbência do poder público "controlar a produção, comercialização e o emprego de técnicas, métodos e substâncias que comportem risco para a vida, a qualidade de vida e o meio ambiente".

Uma vez estabelecidos os limites para o exercício do poder de polícia, pode o poder

\footnotetext{
1 Neste sentido, veja-se: PAZZAGLINI FILHO, Marino. Princípios constitucionais reguladores da administração pública: Agentes Públicos. Discricionariedade Administrativa. Extensão da Atuação do Ministério Público e do Controle do Poder Judiciário. E ainda: CARVALHO, Kildare Gonçalves. Direito constitucional: teoria do Estado e da Constituição. Direito Constitucional Positivo.
} 
público aplicar, coercitivamente, as medidas necessárias para que se evite, ou se minimize, a poluição e a degradação ambientais. Deste modo, sempre que houver risco para a preservação do meio ambiente, deve o poder público intervir, de modo a garantir a adequada proteção do meio ambiente e sua utilização de forma racional, em benefício da sociedade.

\subsection{Princípio da consideração da variável ambiental no processo decisório de políticas de desenvolvimento}

O princípio da consideração da variável ambiental no processo decisório de políticas de desenvolvimento foi previsto pela Declaração do Rio de Janeiro sobre o Meio Ambiente e Desenvolvimento, a qual estabeleceu, em seu princípio de $n^{\circ} 2$, que "a avaliação do impacto ambiental, como instrumento nacional, deve ser empreendida para atividades planejadas que possam vir a ter impacto negativo considerável sobre o meio ambiente, e que dependam de uma decisão de autoridade nacional competente".

Em decorrência desse princípio, sempre que a Administração Pública tenha que se posicionar acerca de determinada política de desenvolvimento, deverá analisar o seu impacto em relação ao meio ambiente.

Tal análise, contudo, não se aplica apenas ao setor público, mas, também à iniciativa privada. A observância desse princípio constituise como meio eficaz para impedir ou, pelo menos, minimizar as lesões causadas ao meio ambiente, permitindo que as ações estatais e também particulares se coadunem com o desenvolvimento ecologicamente sustentável.

Para isso, é necessário que exista uma política voltada para a gestão ambiental. E quando se fala em políticas públicas, na verdade, está se tratando de ações do Estado em prol da coletividade, entre as quais se encontra a proteção ambiental.
Desta forma, conclui-se que, muito embora o desenvolvimento seja um objetivo perseguido por todas as sociedades, ele deve ocorrer levando-se em conta os riscos e danos causados ao meio ambiente, o qual também deve ser protegido.

\subsection{Natureza dos bens jurídicos tutelados}

Justen Filho (2005, p. 45) afirma que a atividade administrativa pode ser desempenhada no atendimento de interesses de titularidade individual, coletiva ou difusa. Para o referido autor "a atividade administrativa do Estado Democrático de Direito subordina-se, então, a um critério fundamental que é anterior à supremacia do interesse público", o que, segundo ele, consiste na "supremacia e indisponibilidade dos direitos fundamentais".

Com base nesse critério conclui-se que, sempre que se estiver diante de um direito fundamental, a atuação estatal estará justificada.

Segundo Canotilho (2007, p. 89):

[...] é fato que, antes de 1988, as Constituições brasileiras não estavam desenhadas de modo a acomodar os valores e as preocupações próprios de um paradigma jurídico-ecológico, padrão normativo este que é invertido na Constituição de 1988, seduzida pela técnica dos conceitos ("equilíbrio ecológico", "ecossistemas"), objetivos (tutela da biodiversidade per se), direitos (direito ao meio ambiente ecologicamente equilibrado), deveres (dever de defender e preservar o meio ambiente para as presentes e futuras gerações), princípios (da prevenção, da precaução e da reparação integral, p. ex.), instrumentos (áreas protegidas e Estudo Prévio de Impacto Ambiental, p. ex.) tudo sob a influência e a inspiração da Ecologia e da gestão ambiental. 
A atuação estatal, neste novo panorama jurídico, deve pautar-se por princípios de direito administrativo e de direito ambiental, os quais devem ser utilizados como orientadores a fim de propiciar a adequada proteção do meio ambiente.

Sobre o tema Fensterseifer (2008, p. 80) assevera que o princípio da precaução faz com que o operador do sistema jurídico passe a interpretar os institutos jurídicos que regem as relações sociais com responsabilidade e cautela. Quando se encontram em risco os direitos fundamentais à vida, à saúde, ao ambiente e o princípio da dignidade humana (tanto das presentes quanto das futuras gerações), de tal modo a observância do princípio da precaução mostra-se fundamental para a adequada proteção desses direitos.

Uma análise mais minuciosa acerca do princípio da precaução demonstra que ele traz, em si, um dever de boa administração do ambiente; por meio de tal princípio a intervenção estatal com vistas à proteção ambiental ganha mais força e credibilidade.

A preocupação com a prevenção de danos ambientais encontra-se presente em nossa Constituição Federal, como por exemplo, ao se exigir a realização de estudo prévio de impacto ambiental para a instalação de obra ou atividade potencialmente causadora de significativa degradação do meio ambiente. Sobre a realização do estudo prévio de impacto ambiental, Fiorillo (2005, p. 40) pondera:

Não se quer com isso inviabilizar a atividade econômica, mas tão-somente excluir do mercado o poluidor que ainda não constatou que os recursos ambientais são escassos, que não pertencem a uma ou algumas pessoas e que sua utilização encontra-se limitada na utilização do próximo, porquanto o bem ambiental é um bem de uso comum do povo.
Para a realização de sua função a Constituição Federal estabeleceu que todos os entes públicos de direito público interno (União, Estados, Distrito Federal e Municípios) têm competência administrativa e, consequentemente, poder de polícia ambiental, para exercer a proteção ao meio ambiente, fiscalizando e aplicando as penalidades cabíveis, conforme disposto no art. 23, VI, da Constituição Federal.

Ante todo o exposto, é possível afirmar que a proteção do meio ambiente pela Administração Pública também se justifica pela natureza dos bens jurídicos tutelados, o que autoriza, inclusive, sua atuação preventiva. A proteção ao meio ambiente repercute diretamente na proteção de outros direitos fundamentais para os seres humanos, tais como o direito à saúde, vida e qualidade de vida.

\section{CONCLUSÕES}

Conforme se pode observar ao longo deste trabalho, os princípios da Administração Pública possuem uma função fundamental, consistente em orientar a atuação estatal em favor da coletividade.

A atuação da Administração Pública deve pautar-se pelos princípios de Direito Administrativo, os quais nortearão a atuação do Estado-Administrador na preservação dos direitos a serem tutelados. Do mesmo modo, face às características inerentes aos direitos da personalidade, a atuação do Estado deve ocorrer da forma mais integral e eficaz possível, pois se trata da proteção de direitos indisponíveis, que exigem uma maior atenção por parte do poder público.

Especificamente em relação à tutela jurídica do meio ambiente, observa-se que os princípios relacionados ao direito ambiental também devem ser considerados, de modo a permitir a adequada proteção de tal direito, nunca se esquecendo que tal proteção tem, como 
objetivo fundamental, a defesa da vida, qualidade de vida e da dignidade da pessoa humana.

A supremacia do interesse público traduzse como princípio orientador da atuação administrativa, de tal forma que os mecanismos e prerrogativas postos à disposição da Administração Pública devem ser utilizados com vistas à satisfação do interesse público, abrangendo, portanto, a defesa do meio ambiente.

Do mesmo modo, o princípio da natureza pública da proteção ambiental, do controle do poluidor pelo Poder Público e o princípio da consideração da variável ambiental no processo decisório de políticas de desenvolvimento exercem papel importante para que o Estado atue em defesa de tal direito.

Acrescente-se, ainda, que a natureza dos bens jurídicos tutelados e o objetivo do Estado em função da realização do bem comum fazem com que este utilize as prerrogativas que the foram outorgadas a fim de propiciar a proteção do meio ambiente.

Deste modo, há de se concluir que diversas são as razões pelas quais impõe-se ao Estado o dever de proteger o meio ambiente para as presentes e futuras gerações, uma vez que tal direito encontra-se relacionamento ligado a proteção da vida humana, qualidade de vida, saúde e, em suma, da dignidade da pessoa humana.

\section{REFERÊNCIAS}

BANDEIRA DE MELLO, C. A. Curso de Direito Administrativo. 9.ed. São Paulo: Malheiros, 1995.

BINENBOJM, G. Uma teoria do direito administrativo: direitos fundamentais, democracia e constitucionalização. Rio de Janeiro: Renovar, 2006.

CARVALHO, K. G. Direito constitucional: teoria do Estado e da Constituição. Direito Constitucional Positivo. Belo Horizonte: Del Rey, 2004.
DALLARI, D. de A. Elementos de teoria geral do Estado. São Paulo: Saraiva, 1989.

DI PIETRO, M. S. Z. Direito administrativo. 18.ed. São Paulo: Atlas, 2005.

FENSTERSEIFER, T. Direitos fundamentais e proteção do ambiente: A dimensão ecológica da dignidade humana. Porto Alegre: livraria do advogado, 2008.

FIORILLO, C. A. P. Curso de direito ambiental brasileiro. 6.ed. São Paulo: Saraiva, 2005.

FREITAS, J. O controle dos atos administrativos e os princípios fundamentais. São Paulo: Malheiros, 1997.

FREITAS, V. P. de. Direito Administrativo e Meio ambiente. 3.ed. Curitiba: Juruá, 2001.

GAVIAO FILHO, A. P. Direito Fundamental ao Ambiente. Porto Alegre: Livraria do advogado, 2005.

CANOTILHO, J. J. G.; LEITE, J. R. M. (org.). Direito constitucional ambiental brasileiro. São Paulo: Saraiva, 2007.

JUSTEN FILHO, M. Curso de Direito

Administrativo. São Paulo: Saraiva, 2005.

LANFREDI, G. F. Política ambiental. Busca de efetividade de seus instrumentos. São Paulo: Revista dos tribunais, 2007.

MELLO, O. A. B. de. Princípios Gerais de Direito Administrativo. v. I. 2.ed. São Paulo: Forense, 1979.

MILARÉ, É. Direito do ambiente. 3.ed. São Paulo: Revista dos Tribunais, 2004.

PAZZAGLINI FILHO, M. Princípios constitucionais reguladores da administração pública: Agentes Públicos. Discricionariedade Administrativa. Extensão da Atuação do Ministério Público e do Controle do Poder Judiciário. São Paulo: Atlas, 2003.

SILVA, J. A. da S. Direito Ambiental Constitucional. 3.ed. São Paulo: Malheiros, 2000.

SILVA, J. A. Curso de Direito Constitucional positivo. São Paulo: Revista dos Tribunais, 1989.

SILVA, V. G. da. Legislação ambiental comentada. Belo Horizonte: Editora Fórum, 2004. 